\title{
Эффективность применения селенитов в период вегетации для обогащения чеснока селеном
}

\author{
Efficiency of application of selenites in the growing season for enrichment of garlic with \\ selenium
}

\section{Поляков А.В., Алексеева Т.В.}

\section{Аннотация}

Цель исследования - усовершенствование способа обогащения растений чеснока селеном до уровня суточной нормы потребления путем обработки вегетирующих растений растворами селенитов натрия и калия в сочетании с поверхностно-активными веществами и диметилсульфоксидом. Исследования проведены во ВНИИО - филиале ФГБНУ ФНЦО, в условиях открытого грунта в 2016-2018 годах, на супесчаной почве, содержание гумуса в которой составляло 3,41-3,44\%, $\mathrm{pH}_{\text {кс }}$ 6,7, степень обеспеченности питательными веществами: фосфором - высокая (содержание $\mathrm{P}_{2} \mathrm{O}_{5}$ в слое 0-20 см составляло 22,78-24,62 мг (по Чирикову); калием - низкая, содержание $\mathrm{K}_{2} \mathrm{O}$ в слое 20 см - 10,38-17,88 мг (по Масловой). Для улучшения минерального питания растений осенью под основную обработку в почву вносили калий хлористый в дозе 50 г/м² , в период вегетации проводили подкормки растений: первую, в фазе начала интенсивного роста листьев - аммиачной селитрой - 30 г/м², вторую, через две недели после первой сульфатом калия - 50 г/ $\mathrm{M}^{2}$. Погодные условия в течение периода исследований были благоприятны для выращивания чеснока. Поливы проводили по мере подсыхания верхнего слоя почвы. Исследования проведены на чесноке озимом сорта Гладиатор. Схема опытов предполагала предпосадочное замачивание зубков в течение 30 мин. и последующую двукратную обработку вегетирующих растений 0,1\%-ным раствором селенита натрия и калия в сочетании с поверхностно активными веществами (1\%) и диметилсульфоксидом (1\%): первый раз в фазе начала интенсивного роста листьев и второй - через три недели. Установлено, что некорневая обработка растений селенитом натрия была в 2,3 раза, а селенитом калия в 5,8 раза эффективнее, чем корневая. Сделан вывод о том, что луковицы чеснока, полученные, в результате некорневой обработки растений 0,1\%-ным раствором селенита натрия и калия в сочетании с поверхностно активными веществами и диметилсульфоксидом содержат в 145,3-169,8 раза больше селена, чем контроль, что позволяет получить зубки, содержащие селен в концентрации 6,83-7,98 мг/ кг. Суточная норма потребления чеснока составляет примерно 10 г, средняя потребность в селене составляет от 30 до 70 мкг. Учитывая, что содержание селена в обогащенной продукции составит 68,3 79,8 мкг/10 г чеснока предложенный способ обогащения позволяет в полной мере удовлетворить суточную потребность организма человека в этом микроэлементе.

Ключевые слова: чеснок, зубки, селен, способы обогащения, селениты, поверхностно активное вещество.

Для цитирования: Поляков А.В., Алексеева Т.В. Эффективность применения селенитов в период вегетации для обогащения чеснока селеном // Картофель и овощи. 2020. №1. С. 12-14. https://doi.org/10.25630/PAV.2020.17.57.003

\section{Polyakov A.V., Alekseeva T.V.}

\section{Abstract}

The aim of investigation was to improve the method of enrichment of garlic plants with selenium to the level of daily consumption rate by treatment of vegetative plants with solutions of sodium and potassium selenites in combination with surfactants. The investigations were carried out at ARRIVG - branch of FSCVG, in open ground in 2016-2018, on sandy loam soil with humus content of $3.41-3.44 \%, \mathrm{pH}_{\mathrm{KCl}} 6.7$, content of phosphorus $\left(\mathrm{P}_{2} \mathrm{O}_{5}\right)$ in the layer $0-20 \mathrm{~cm}$ was 22.78-24.62 mg (Chirikov); content of potassium $\left(\mathrm{K}_{2} \mathrm{O}\right)-10.38-17.88 \mathrm{mg}$ (Maslova). To improve mineral nutrition of plants fall under the basic treatment in the soil was added potassium chloride at a dose of $50 \mathrm{~g} / \mathrm{m}^{2}$ during the growing season were plant nutrition: first, in the early phase of intensive growth of leaves - ammonium nitrate $-30 \mathrm{~g} / \mathrm{m}^{2}$, the second, two weeks after the first potassium sulphate and $50 \mathrm{~g} / \mathrm{m}^{2}$. Weather conditions during the period of growth were favorable for growing garlic. Watering was carried out at the periods where the top layer of soil was dried. Studies were carried out on variety Gladiator of winter garlic. The experimental design included soaking the cloves for 30 minutes before planting, and subsequent double treatment of vegetating plants with $0.1 \%$ solution of sodium and potassium selenite in combination with surfactants (1\%) and dimethyl sulfoxide $(1 \%)$ : the first time in the phase of the beginning of intense leaf growth and the second time after 3 weeks. As a result of the investigations it was found that non-root treatment of plants with solutions containing selenium was more effective than root treatment. Non-root top dressing with sodium selenite was in 2.3 times, and potassium selenite - in 5.8 times more effective than root. It is concluded that garlic bulbs obtained as a result of non-root treatment of plants with $0.1 \%$ solution of sodium and potassium Selenite in combination with surfactants and dimethylsulfoxide contain 145.3-169.8 times more selenium than control, which allows to obtain teeth containing selenium in a concentration of $6.83-7.98 \mathrm{mg} / \mathrm{kg}$. The daily consumption rate of garlic is approximately $10 \mathrm{~g}$, the average need for selenium element is from 30 to 70 micrograms. Because of content of selenium in enriched products consisted of $68.3-79.8 \mathrm{mcg} / 10$ $\mathrm{g}$ of garlic, the proposed method of enrichment allows to fully satisfy the daily need of the human body at this microelement.

Key words: garlic, clove of garlic, selenium, enrichment methods, sodium selenite, surfactant.

For citing: Polyakov A.V., Alekseeva T.V. Efficiency of application of selenites in the growing season for enrichment of garlic with selenium // Potato and vegetables. 2020. №1. Pp. 12-14 (In Russ.). https://doi. org/10.25630/PAV.2020.17.57.003
X имический состав - важный показатель качества растительной продукции. Все макро-, мезои микроэлементы, белки, жиры, углеводы, человек получает с пищей, поэтому их качественный и количественный состав оказывает большое влияние на жизнедеятельность и здоровье человека.
Микроэлементы - необходимый компонент для здоровья человека. Суточная потребность в них невелика, но при постоянном их дефиците увеличиваются риски возникновения различных заболеваний. К таким элементам относится селен.

В организме растений и животных селен способен замещать серу в при- родных соединениях, в частности, в аминокислотах, образуя селеноцистеин и селенометионин. Входя в состав аминокислот, этот элемент проявляет высокую противораковую активность. Селен входит в состав ряда ферментов, которые обладают антиоксидантными свойствами. Помимо этого, селен обладает иммуностиму- 


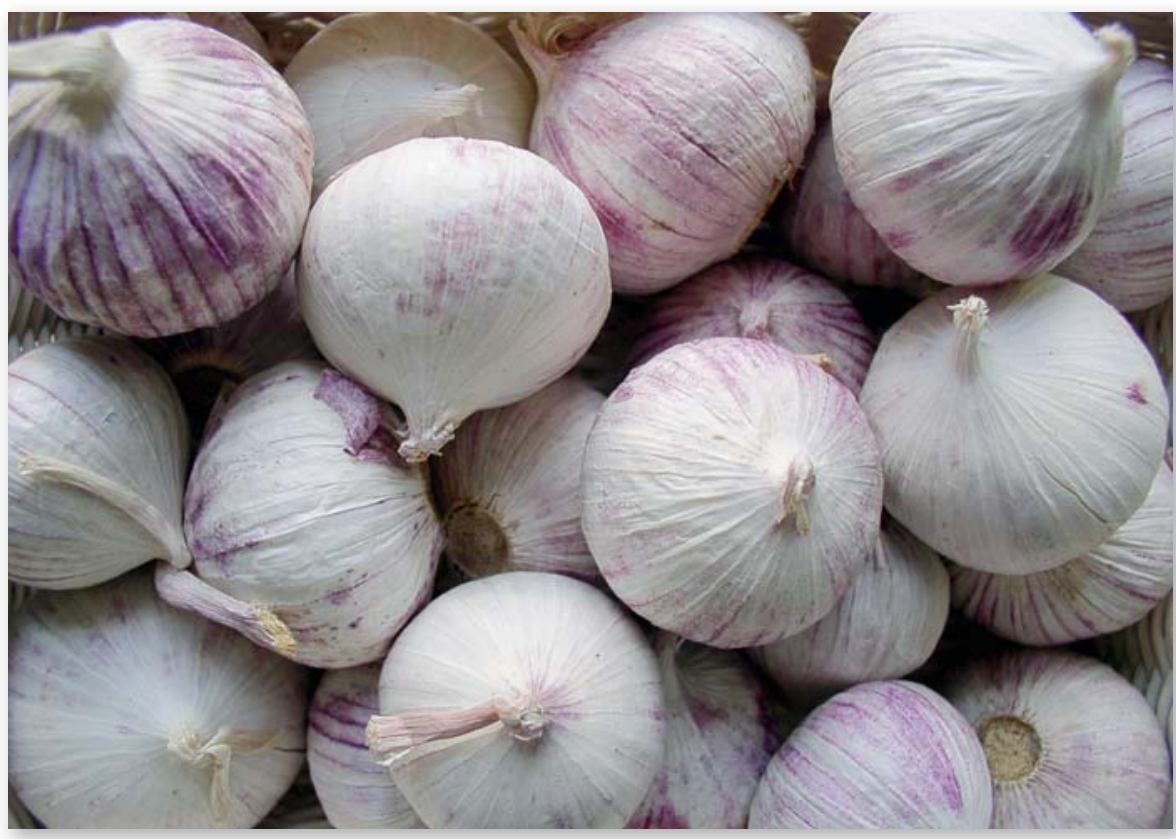

Однозубковые луковицы чеснока озимого сорта Гладиатор

лирующим действием, участвует в метаболизме йода, способствует выведению тяжелых металлов. Подобные свойства важны для профилактики и лечения сердечно-сосудистых и онкологических заболеваний [1, 2].

Рекомендуемые суточные нормы потребления селена зависят от пола и возраста человека и варьируют от 30 до 70 мкг. Многие растения могут накапливать этот элемент в своих тканях. Так, согласно литературным данным, чеснок может накапливать до 200 мкг селена на кг сырой массы [3, 4, 5].

Известен способ обогащения чеснока селеном, который заключается в совместном внесении в почву селената натрия и жидких удобрений Fertika lux (N - 1,6; $\mathrm{P}_{2} \mathrm{O}_{5}-2,0 ; \mathrm{K}_{2} \mathrm{O}-2,7$; $\mathrm{Fe}-0,01 ; \mathrm{B}-0,002 ; \mathrm{Cu}-0,001 ; \mathrm{Mn}-$ 0,$01 ;$ Mo - 0,002; Zn - 0,001\%). Общая доза селената натрия составляла 75 мг/м². Внесение проводили частями в течение 2,5 месяцев. При каждом внесении к 7,5 мг селената натрия добавляли 25 мл удобрения Fertika и pacтвор доводили до 10 л в расчете на

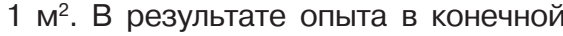
продукции содержание селена (порошке, полученном из луковиц) повысилось в 16,7 раз по сравнению с конт-

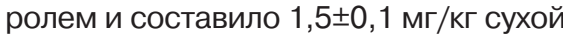
массы. При этом отмечено, что этот метод позволил снизить уровень содержания $\mathrm{Cd}, \mathrm{Pb}, \mathrm{Al}, \mathrm{Ni}, \mathrm{Cu}$ в полученной продукции - порошке чеснока [6].

Целью нашего исследования было усовершенствование способа обогащения растений чеснока селеном до уровня суточной нормы потребления путем обработки вегетирующих растений растворами селенитов в сочетании с поверхностно-активными веществами (ПАВ).

Условия, материалы и методы исследований

Опыты

BO

Всероссийском научно-исследовательском институте овощеводства филиале ФГБНУ ФНЦО (Московская область, Раменский р-н) в условиях открытого грунта в 2016-2018 годах.

Почва опытного участка супесчаная, содержание гумуса в слое 0-20 см - 3,41-3,44\%; в слое 2040 см - 2,91-3,02\%. Реакция проведены

среды нейтральная: $\mathrm{pH}_{\mathrm{kcl}}$ 6,7. Гидролитическая кислотность 0,720,92 мг-экв/100 г, сумма поглощенных оснований 46-50 мг-экв/100 г. Степень обеспеченности питательными веществами: фосфором высокая (содержание $\mathrm{P}_{2} \mathrm{O}_{5}$ в слое 0-20 см составляла 22,78-24,62 мг (по Чирикову); калием - низкая, содержание $\mathrm{K}_{2} \mathrm{O}$ в слое 20 см - 10,3817,88 мг (по Масловой). Удельная масса почв пахотного слоя 0-25 см -

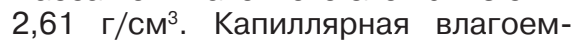
кость 43-44\%. Гигроскопическая влажность 8,25\%.

Для улучшения минерального питания растений в почву вносили калийхлористый в дозе 50 г/м², в период вегетации растений использовали подкормки: первую, в фазе начала интенсивного роста листьев - аммиачной селитрой - 30 г/м², вторую, через две недели после первой сульфатом калия - 50 г/ $\mathrm{M}^{2}$. Исследования проведены на чесноке озимом сорта Гладиатор.

Погодные условия в течение периода исследований были благоприятны для выращивания чеснока. Полив растений проводили по мере подсыхания верхнего слоя почвы.

Для обогащения чеснока селеном проводили трехкратную обработку зубков и вегетирующих растений растворами селенита натрия и селенита калия в концентрации 0,1\%, растворах, содержащих 1\% диметилсульфоксида (ДМСО) или 1\% ПАВ. В качестве контроля была использована вода.

При первой обработке зубки в течение 30 мин. выдерживали в растворе, при двух последующих - обрабатывали растения в период вегетации: первый раз в фазе начала интенсивного роста лис-

Таблица 1. Содержание селена в образцах чеснока в 2016-2017 годах, мкг/г

\begin{tabular}{|l|c|c|}
\hline \multicolumn{1}{|c|}{ Вариант опыта } & Некорневая подкормка & Корневая подкормка \\
\hline Контроль & $0,04 \pm 0,006$ & $0,04 \pm 0,005$ \\
\hline Селенит натрия & $0,47 \pm 0,057$ & $0,2 \pm 0,024$ \\
\hline Селенит калия & $0,58 \pm 0,069$ & $0,1 \pm 0,013$ \\
\hline Селенит цинка & $0,07 \pm 0,01$ & $0,03 \pm 0,004$ \\
\hline
\end{tabular}

Таблица 2. Содержание селена в зубках чеснока озимого при применении селенитов натрия и калия в 2016-2017 годах, мкг/кг

\begin{tabular}{|l|c|c|}
\hline \multirow{2}{*}{\multicolumn{1}{|c|}{ Вариант обработки }} & \multicolumn{2}{|c|}{ Содержание селена } \\
\cline { 2 - 3 } & МКГ/КГ & кратность превышения \\
\hline Контроль & $47,0 \pm 7,0$ & - \\
\hline Селенит натрия + ДМСО & $7390,0 \pm 740,0$ & 157,2 \\
\hline Селенит натрия + ПАВ & $7980,0 \pm 800,0$ & 169,8 \\
\hline Селенит калия + ДМСО & $6830,0 \pm 680,0$ & 145,3 \\
\hline Селенит калия + ПАВ & $1380,0 \pm 140,0$ & 29,4 \\
\hline
\end{tabular}


тьев и второй раз - через три недели. Опыт заложен в четырехкратной повторности, учетная площадь одной делянки $1 \mathrm{M}^{2}$, посев рядовой расстояние между рядками 25 см, между растениями в рядке $10 \mathrm{~cm}$, длина рядка 1 м. Расход рабочей жидкости составлял 100 мл/м².

Содержание селена определяли по методу доктора Скального [7]. Анализ выполнен в ООО «Микронутриенты» методом массспектрального анализа.

\section{Результаты исследований}

В исследованиях, проведенных Ю.А. Хрыкиной, показана высокая эффективность применения корневой подкормки чеснока удобрениями пролонгированного действия, содержащими селенат натрия. Уровень накопления селена в зависимости от сорта составил от 876 мкг/кг до 1600 мкг/кг. Некорневое обогащение, проведенное неорганическим селенатом натрия и органическим соединением Селекор, имели более низкие значения накопления селе- на, которые не превышали 300 мкг/кг при обработке растений селенатом натрия и 200 мкг/кг при обработке растений Селекором [4].

В наших же исследованиях при использовании растворов селенитов натрия, калия и цинка при различных способах внесения отмечено преимущество некорневой подкормки. Использование селенитов натрия и селенита калия при некорневой подкормке позволяло в 2,5-14,5 раз повысить содержание селена в луковицах. Выявлено, что некорневая подкормка селенитом натрия была в 2,3 раза, а селенитом калия в 5,8 раза эффективнее, чем корневая. Применение селенита цинка не было эффективным как при корневой, так и некорневой подкормке (табл. 1).

Для повышения эффективности обогащения луковиц селеном к растворам селенитов добавляли ДМСО и ПАВ. Анализ полученных данных показал, что после обработки вегетирующих растений чеснока раство- рами селенитов натрия и калия, содержащих ДМСО или ПАВ, содержание селена в зубках резко возрастало. Содержание селена в зубках чеснока при применении селенита натрия таким способом увеличилось в 157,2 и 169,8 раза и составило 7,4 и 8,0 мг/кг, а при использовании селенита калия в 145,3 и 29,4 раза и составило 6,3 и 1,3 мг/кг (табл. 2).

\section{Выводы}

Ввиду того, что рекомендуемые суточные нормы потребления селена составляют от 30 до 70 мкг, а чеснока 10 г на человека, то для удовлетворения потребности в селене, в этом количестве чеснока должно содержаться 3070 мкг селена. Некорневая обработка чеснока в период вегетации селенитом натрия и калия в сочетании с ПАВ и ДМСО, позволяет получить зубки, содержащие селен в концентрации 6,83-7,98 мг/кг или 68,3-79,8 мкг/10 г чеснока, что в полной мере удовлетворяет суточную потребность взрослого человека в этом микроэлементе.

\section{References}

1.Голубкина Н.А., Папазян Т.Т. Селен в питании: растения, животные, человек. М.: Печатный город, 2006. С. 9-16, 135-141.

2.Brown K.M., Arthur J.R. Selenium, selenoproteins and human health: a review // Public Health Nutrition. 2001. Vol. 4. Pp. 593-599.

3.Гореликова Г.А. Теоретические и практические аспекты разработки пищевых продуктов, обогащенных селеном: монография. Кемерово, 2008. С.11-18.

4.Хрыкина Ю.А. Оценка и выделение исходного материала чеснока озимого на накопление селена: автореф. дис. ... канд. с.-х. наук. Москва, 2009. 25 с.

5.Капустина Л. Необыкновенные свойства обыкновенного чеснока // Овощеводство. 2014. №10. С. 67-69.

6.Голубкина Н.А. и др. Порошок чеснока, обогащенного селеном // Микроэлементы в медицине. 2018. №19 (1). С. 43-50.

7.Метод доктора Скального®. Лицензия ЛО-77-01-006064 [Электронныйресурc]URL:https://synapsenet.ru/searchorganization / organization / 1037729014850-ooo-mikronutrienti/licenzii.

8.Чеснок - источник органического селена / А.В. Поляков, С.В. Логинов, Т.В. Алексеева, Д.Б. Петренко // Наука на благо человечества-2018: сборник научных статей преподавателей и аспирантов по итогам Междунар. науч. конф. молодых ученых, аспирантов и студентов (МГОУ, г. Москва, 16-27 апреля 2018 года). Москва, 2018. С. 45-49.
1.Golubkina N.A., Papazjan T.T. Selenium in the diet: plants, animals, people. M.: Pechatnyj gorod, 2006. Pp. 9-16, 135-141 (In Russ.).

2.Brown K.M., Arthur J.R. Selenium, selenoproteins and human health: a review. Public Health Nutrition. 2001. Vol. 4. Pp. 593-599.

3.Gorelikova G.A. Theoretical and practical aspects of the development of food products enriched with selenium: monograph. Kemerovo, 2008. Pp. 11-18 (In Russ.).

4.Hrykina Ju.A. Evaluation and isolation of the source material of winter garlic on the accumulation of selenium: abstract ... cand. agri. sci. Moscow. 2009. 25 p. (In Russ.).

5.Kapustina L. The extraordinary properties of ordinary garlic. Olericulture. 2014. №10. Pp. 67-69 (In Russ.).

6. Golubkina N.A. et al. Garlic powder enriched with selenium. Trace elements in medicine. 2018.No19 (1). Pp. 43-50 (In Russ.).

7.Dr. Skal'nyi method®. License LO-77-01-006064 [web resource]. URL: https:// synapsenet.ru / searchorganization / organization / 1037729014850-ooo-mikronutrienti / licenzii. Access date: 29.09.2019 (In Russ.).

8.Garlic-a source of organic selenium/A.V.Poljakov, S.V. Loginov, T.V. Alekseeva, D.B. Petrenko // Science for the benefit of mankind-2018: collection of scientific articles of teachers and postgraduates on the results of international conferences. science. Conf. young scientists, postgraduates and students (Moscow state University, Moscow, April 16-27, 2018). Moscow. 2018. Pp. 45-49 (In Russ.).

\section{Об авторах}

Поляков Алексей Васильевич, доктор биолог. наук, профессор, гл.н.с., зав. отделом биотехнологии и инновационных проектов Всероссийского научно-исследовательского института овощеводства - филиала ФГБНУ ФНЦО (ВНИИО - филиал ФГБНУ ФНЦО); и.о. заведующего кафедры ботаники и прикладной биологии Московского государственного областного университета (МГОУ). Тел. +7 (906) 707-69-47. E-mail: vita100plus@yandex.ru

Алексеева Татьяна Вячеславовна, канд. с.-х. наук, м.н.с. отдела биотехнологии и инновационных проектов ВНИИО - филиал ФГБНУ ФНЦО; старший преподаватель кафедры ботаники и прикладной биологии МГОУ. Тел. +7 (915) 460-26-05. E-mail: matilda8691@gmail.com

\section{Author details}

Polykov A.V., Dr. Sci. (Biol.), prof., head of biotechnological and innovation project department, All-Russian Research Institute of Vegetable Growing - branch of Federal State Budgetary Research Enterprise Federal Research Center of Vegetable Growing (ARRIVG - branch of FSBSI FSCVG); acting head of department botany and applied biology, Moscow Region State University (MRSU). Phone +7 (906) 7076947.E-mail: vita100plus@yandex.ru

Alekseeva T.V., Cand. Sci. (Agr.), junior research fellow, department of biotechnology and innovation projects, ARRIVG branch of FSBSI FSCVG; senior lecturer, department botany and applied biology, MRSU. Phone + 7 (915) 4602605 . E-mail: matilda8691@gmail.com 